\title{
The Performance of the Abbott Real Time MTB RIF/INH Compared to the MTBDRplus V2 for the Identification of MDR-TB Among Isolates
}

This article was published in the following Dove Press journal: Infection and Drug Resistance

\author{
Anura David (D) \\ Lyndel Singh' \\ Pedro Da Silva $\mathbb{D}^{1,2}$ \\ Lesley Scott $\mathbb{D}^{\prime}$ \\ Wendy Stevens ${ }^{1,2}$ \\ 'Department of Molecular Medicine and \\ Haematology, University of the \\ Witwatersrand, Johannesburg, South \\ Africa; ${ }^{2}$ National Priority Program, \\ National Health Laboratory Services, \\ Johannesburg, South Africa
}

Background: The GenoType MTBDRplus V2 line-probe assay (LPA) is routinely used in clinical patient management to characterise the susceptibility of Mycobacterium tuberculosis complex to rifampicin (Rif) and isoniazid (INH) directly from sputum and cultured isolates. The laboratory workflow requires skill and three separate areas to minimize contamination and banding pattern interpretation requires experienced laboratory personnel. We explored the use of the RT MTB RIF/INH assay performed on the Abbott $m 2000$ platform as an alternative laboratory platform.

Methods: Isolates ( $\mathrm{n}=93$ ) consisting of fully susceptible, Rif- or INH-mono-resistant and multi-drug resistant (MDR) strains were tested on both MTBDRplus v2 and RT MTB RIF/ $\mathrm{INH}$ assays. Both assays target the $\operatorname{rpoB}, k a t G$ and inhA genes for resistance-detection mutations. Concordance was assessed using percent agreement and the kappa statistic. Those specimens with discordant results were further assessed using Sanger sequencing.

Results: A total of $89 \%(83 / 93)$ of cultured isolates generated successful results on the RT MTB/RIF-INH assay and MTBDRplus assays. Of the 10 discordant results, where sequencing was used as the reference method, the RT MTB RIF/INH assays misclassified six resistance isolates, while the LPA misclassified seven.

Discussion: Overall, the RT MTB RIF/INH demonstrated good agreement with the LPA, and a better correlation with sequencing on discrepant isolates specifically with mutations occurring in codon 511 of the rpoB gene. The RT MTB RIF/INH therefore can be used to complement existing laboratory algorithms determining Rif and INH resistance profiles, with less emphasis on manual laboratory processing.

Keywords: molecular diagnostics, tuberculosis, line-probe assay

\section{Introduction}

Molecular technology is well applied in current tuberculosis (TB) diagnostic algorithms, with no better example than the Xpert MTB/RIF (Xpert), with a footprint in $>130$ countries. ${ }^{1}$ Although this technology simultaneously detects the presence of Mycobacterium tuberculosis complex (MTBC) and susceptibility to rifampicin (Rif) across several clinical specimen types, it is not designed to detect resistance to isoniazid (INH). According to the World Health Organisation (WHO), globally 8\% TB cases show monoresistance to INH. In South Africa's current TB diagnostic algorithm, INH resistance is detected using the GenoType MTBDRplus V2 line-probe assay $\{\mathrm{LPA}\}^{2}$ (HAIN Lifesciences, Nehren, Germany), that can be performed directly on decontaminated sputum and indirectly off Mycobacterial Growth Indicator tubes (MGIT)
Correspondence: Anura David Department of Molecular Medicine and Haematology, University of the Witwatersrand, 7 York Road, Parktown, Johannesburg 2193, South Africa Tel +27 100013914

Email anura.david@witshealth.ac.za
Infection and Drug Resistance 2020:13 330I-3308 
isolates. This LPA is based on DNA Strip technology and is used for the determination of resistance to Rif and INH in MTBC. ${ }^{3-6}$ Version 1 of this assay was endorsed by the WHO in $2008 .^{7}$ At the time, the assay had the advantage of enabling rapid detection of $\mathrm{MTBC}$ and resistance profiling (in less than 48 hours) and was also available as a high-throughput technology (48 specimens per batch using the GT Blot 48 [HAIN Lifesciences, Nehren, Germany]). However, due to the performance of the assay, the WHO recommended the version 1 LPA for use on smear-positive sputum specimens only. ${ }^{7}$ In 2012, version 2 of the LPA became available with recommendations for use on both smear-positive and smearnegative sputum specimens. However, despite its improvements, assay performance is still affected by bacillary load. ${ }^{5}$ The sensitivity and specificity of the LPA assay for MTBC detection varies across studies. A study conducted in South Africa demonstrated a sensitivity of $73.1 \%$ (95\% CI: $59.8-$ $83.2 \%$ ) and a specificity of $100 \%(95 \% \text { CI: } 80.6-100 \%)^{6}$ whilst in Ethiopia, the sensitivity and specificity of the assay was determined as 96.4\% (95\% CI: 81.7-99.9) and 100\% (95\% CI: 88.8-100) ${ }^{4}$ respectively, with other countries reporting sensitivities around $88-99 \%{ }^{8-10}$ Sensitivity of the LPA on smear-negative sputum in the above-mentioned studies was reported as 57-79\%. For Rif resistance, the LPA assay demonstrates sensitivity ranging between $88.2 \%$ and $98.1 \%$ and for INH resistance, between $92 \%$ and $94 \% .^{8-10}$ LPA performance on cultured isolates has previously been evaluated with a sensitivity for Rif resistance of $100 \%(95 \%$ CI: 76.8-100) and specificity of 87.9\% (95\% CI: 78.9-94.1); INH resistance detection with a sensitivity of $100 \%(95 \% \mathrm{CI}$ : 91.8-100) and specificity of $94.4 \%$ (95\% CI: 84.6-98.8). ${ }^{11}$ However, the LPA is labour intensive since the DNA extraction, preparation for amplification, hybridisation (if using the Twincubator) and result interpretation are manual processes (unless using a Genoscan ${ }^{\circledR}$ for automated result interpretation). The operation and interpretation requires a higher degree of skill and a laboratory infrastructure with three separate rooms to prevent contamination. An in-house study investigating the subjectivity of LPA strip interpretation using different light sources (personal communication Robert Coombs) demonstrated that strip interpretation is difficult and subjective due to differing band intensities read under different lighting conditions (normal fluorescent lighting, sunlight and an i-Phone light). Of 15 strips prepared from clinical isolates and read by eight individuals, four strips produced varying outcomes with the highest discordance being seen under normal fluorescent lighting. This led to an investigation of alternative molecular platforms that potentially could provide less subjective result outcomes.

One such technology is the m2000 (Abbott Molecular, Des Plaines, IL, United States), which in South Africa has shown to be a reputable and robust platform for highthroughput HIV-1 testing since $2010,{ }^{12}$ and also investigated as a platform for integrated HIV/TB diagnostics. The RT MTB assay which is performed on the $m 2000$ system is a qualitative in vitro molecular assay for the direct detection of MTBC, with an optional reflex feature to the RT MTB RIF/INH assay for detection of Rif and INH resistance. The pooled sensitivity of RT MTB for detecting TB is reported in a meta-analysis as 96.0\% (95\% CI: 88.0-99.0) and specificity of $97 \%$ (95\% CI: 93.0-99.0). ${ }^{13}$ For DR-TB, four studies were included to evaluate the diagnostic accuracy of RT MTB RIF/INH. The pooled sensitivity was $88 \%$ (95\% CI, 82.0-93.0) and specificity 99\% (95\% CI: 96.0-99.0). ${ }^{13}$ Studies from Johannesburg, South Africa ${ }^{14}$ and Hong Kong ${ }^{15}$ similarly reported that $30 \%$ specimens identified by the RT MTB assay could not generate a result with the reflex assay, RT MTB RIF/INH, due to the limit of detection (LOD). Although this is a disadvantage compared to the Xpert or Xpert MTB/RIF Ultra (Ultra) assays, these latter assays are unable to report INH susceptibility. The ability of the RT MTB RIF/INH assay to be performed either in direct testing mode or in reflex mode following a positive RT MTB result ${ }^{16}$ provides flexibility for this assay to be performed on MGIT cultures isolates, which have higher bacillary loads. The performance of the RT MTB RIF/INH was therefore investigated in comparison to the LPA, as an option to improve laboratory workflow through automation with the $m 2000$ system and capitalize on the large footprint (>400 m2000 instruments supported by $>50$ field service support staff) across sub-Sahara African countries (personal communication Abbott Molecular (November 2019)).

\section{Materials and Methods}

\section{Study Isolates}

Stored cultured isolates $\left(-80^{\circ} \mathrm{C}\right)$ from the Clinical Laboratory Services biorepository $(n=32)$ as well as residual culture isolates from the National Health Laboratory Services (NHLS) Mycobacteriology Referral Laboratory $(n=61)$ were tested in this evaluation. Cultured isolates $(1 \mathrm{~mL})$ were re-subcultured into MGIT. Once these flagged positive on the MGIT 960 instrument (Becton Dickinson, Sparks, MD, USA) and confirmed to be positive for acid-fast bacilli (AFB) by Ziehl Neelsen (ZN) staining, testing 
was performed using the LPA and the RT MTB RIF/INH assays according to the manufacturer's instructions ${ }^{17}$ and as previously described. ${ }^{2,14}$

\section{Genotyping Assay Description}

For the LPA, manual DNA extraction was performed on $1 \mathrm{~mL}$ of culture using the GenoLyse ${ }^{\circledR}$ (HAIN Lifesciences, Nehren, Germany) extraction kit, followed by amplification using a Techne TC-512 thermocycler (Labotec Pty Ltd, Johannesburg, South Africa) and hybridisation using the automated GT-Blot 48. Testing was performed in two batches, to accommodate the 93 tests, followed by a manual interpretation of the strips. The LPA assay identifies Rif resistance through the detection of the most significant associated mutations of the $r p o B$ gene (coding for the $\beta$-subunit of the RNA polymerase). For detection of INH resistance, the $k a t G$ gene (coding for the catalase peroxidase) and the promoter region of the inhA gene (coding for the NADH enoyl ACP reductase) are examined. The assay is, therefore, able to provide information on the level of INH resistance detected (mutations in the $\mathrm{katG}$ regions are associated with high-level resistance while mutations in the inhA gene region are associated with low-level INH resistance). In certain instances, the absence of a wildtype (WT) band with an absence of the corresponding mutant band indicates that a specific resistance conferring mutation cannot be identified and resistance can then only be inferred. Updates to the interpretation of the LPA strips in the HAIN Lifescience Instructions for Use (IFU) resulted in a reevaluation of strip interpretation in 2019. ${ }^{18}$

For the RT MTB RIF/INH assay, $500 \mu \mathrm{L}$ of culture was inactivated in a ratio of 1 (culture): 3 (inactivation reagent) for a period of 1 hour. This was followed by nucleic acid extraction on the m2000sp instrument and amplification and detection on the m2000rt instrument. For each of the three gene targets, results are provided as WT if no resistance is detected. If resistance is detected, the absence of the relevant probe is provided for the $r p o B$ gene or the relevant mutation is provided for the $k a t G$ and $i n h A$ genes. Similarly, to the LPA, inferred resistance can also be detected in the RT MTB RIF/INH assay, where specific mutation information is not provided.

Those specimens with discordant results were further assessed using targeted Sanger sequencing (performed at the South African Medical Research Council Centre for tuberculosis research at Stellenbosch University) of the rpoB, kat $G$ and inhA genes.

Concordance between the RT MTB RIF/INH reflex assay and the LPA assay was assessed using percent agreement and the kappa statistic using Stata version 14 (StataCorp, College Station, TX, USA).

\section{Ethics Statement}

Ethics approval was obtained from the University of the Witwatersrand Human Research Ethics Committee for the use of residual specimens received for routine diagnostic testing (M150160: Research and Development (R\&D) Programme).

\section{Results \\ Biorepository Isolate Composition Determined by the Standard-of-Care (SOC) MTBDRplus V2 and the RT MTB RIF/INH Assays}

Of the 87 isolates, which produced results on the LPA, 83 produced valid resistance profiles. Similarly, on the RT MTB RIF/INH assay, 83 isolates produced valid resistance profiles but not all reportable results were produced on the same isolates as the LPA. Both assays, therefore, produced indeterminate results on the same number of isolates $(\mathrm{n}=10)$. No repeat testing was performed on either assay. Table 1 outlines the standard of care (SOC) results reported by LPA and the results reported by the RT MTB RIF/INH assay. The LPA categorised the resistant isolates

Table I Rif and INH Resistance Profile Determined by the SOC MTBDRplus V2 and the RT MTB RIF/INH

\begin{tabular}{|c|c|c|c|c|c|c|}
\hline \multirow[t]{2}{*}{ SOC MTBDRplus V2 $(n=87)$} & \multicolumn{6}{|c|}{ RT MTB RIF/INH } \\
\hline & $\begin{array}{l}\text { Below } \\
\text { LOD }\end{array}$ & Error & $\begin{array}{l}\text { Rif/INH } \\
\text { Susceptible }\end{array}$ & $\begin{array}{l}\text { Rif/INH } \\
\text { Resistant }\end{array}$ & $\begin{array}{l}\text { Rif Mono- } \\
\text { Resistant }\end{array}$ & $\begin{array}{l}\text { INH Mono- } \\
\text { Resistant }\end{array}$ \\
\hline$n=4(4.6 \%)$ Indeterminate & 2 & & I & 1 & & \\
\hline$n=17$ (I9.5\%) Rif/INH susceptible & & & 13 & & 4 & \\
\hline$n=34$ (39.1\%) Rif//NH resistant & 3 & & 1 & 25 & 2 & 3 \\
\hline $\mathrm{n}=19(21.8 \%)$ Rif mono-resistant & 2 & 1 & 1 & & 15 & \\
\hline$n=13(14.9 \%)$ INH mono-resistant & 2 & & & $\mathrm{I}$ & & 10 \\
\hline
\end{tabular}


as $51.5 \%(34 / 66)$ resistant to both Rif and INH, $28.8 \%$ (19/66) resistant to Rif only and $19.7 \%$ (13/66) resistant to INH only. $19.5 \%(17 / 87)$ were categorised as susceptible to Rif and INH and 4.6\% (4/87) indeterminate for both Rif and INH.

\section{Rif Genotyping}

The most common rpoB gene mutation identified by the LPA assay as outlined in Table 2 was the S531L ( $\mathrm{n}=15$ [28.3\%]), followed by the D516V mutation in $18.9 \%(n=10)$ of isolates. The LPA inferred resistance in $26.4 \%(n=14)$ of isolates. On the RT MTB RIF/INH assay (Table 3), Probe 4 was missing in $35.3 \%$ ( $n=18)$ of isolates indicating a mutation $/ \mathrm{s}$ in codons $531-533$ of the rpoB gene. $21.6 \%(\mathrm{n}=11)$ of isolates demonstrated a missing Probe 2 with another $21.6 \%$ demonstrating a missing Probe 5 indicating mutation/s in codons 513-516 and 519-522, respectively. Inferred resistance was detected in one isolate on the RT MTB RIF/INH assay. Of the 73 isolates which demonstrated valid Rif resistant results for both assays, $89.0 \%(n=65)$ showed substantial agreement between the 2 assays (Kappa: 0.765).

Table 2 Summary of Mutations Reported by the GenoType ${ }^{\circledR}$ MTBDRplus V2 Assay

\begin{tabular}{|c|c|c|c|c|}
\hline Drug & \multicolumn{2}{|c|}{ Mutation } & $\mathbf{n}$ & $\%$ \\
\hline \multirow[t]{12}{*}{ Rif } & \multicolumn{2}{|l|}{ Total } & 53 & $100 \%$ \\
\hline & \multicolumn{2}{|l|}{ S53IL } & 15 & $28.3 \%$ \\
\hline & & 10 & $18.9 \%$ \\
\hline & \multicolumn{2}{|c|}{ Codons $510-519$} & 7 & $13.2 \%$ \\
\hline & \multicolumn{2}{|l|}{ H526Y } & 5 & $9.4 \%$ \\
\hline & \multicolumn{2}{|l|}{$\Delta$ wt7 } & 4 & $7.6 \%$ \\
\hline & \multicolumn{2}{|l|}{$\Delta \mathrm{w}+8$} & 4 & $7.6 \%$ \\
\hline & \multicolumn{2}{|c|}{$\Delta w t 2-3$} & 3 & $5.7 \%$ \\
\hline & \multicolumn{2}{|l|}{$\Delta w t 4$} & 2 & $3.8 \%$ \\
\hline & \multicolumn{2}{|l|}{$\Delta w+2-4$} & I & $1.9 \%$ \\
\hline & \multicolumn{2}{|l|}{ H526D } & I & $1.9 \%$ \\
\hline & \multicolumn{2}{|l|}{ N5181 } & 1 & $1.9 \%$ \\
\hline \multirow[t]{10}{*}{$\mathrm{INH}$} & \multicolumn{2}{|l|}{ Total } & \multirow[t]{2}{*}{47} & \multirow[t]{2}{*}{$100 \%$} \\
\hline & katG & $\operatorname{inh} A$ & & \\
\hline & S3I5TI & & 21 & $44.7 \%$ \\
\hline & S3I5TI & T8A & 9 & $19.1 \%$ \\
\hline & & CI5T & 7 & $14.9 \%$ \\
\hline & S3I5TI & $\Delta w t \mid$ & 4 & $8.5 \%$ \\
\hline & S3I5TI & $\mathrm{Cl5T}$ & 3 & $6.4 \%$ \\
\hline & & CI5T; AI6G & I & $2.1 \%$ \\
\hline & & Missing inhA & 1 & $2.1 \%$ \\
\hline & & $\mathrm{T} 8 \mathrm{C}$ & I & $2.1 \%$ \\
\hline
\end{tabular}

Table 3 Summary of Mutations Reported by the Abbott RT MTBRIF/INH Assay

\begin{tabular}{|c|c|c|c|c|}
\hline Drug & \multicolumn{2}{|c|}{ Mutation Information } & $\mathbf{n}$ & $\%$ \\
\hline \multirow[t]{8}{*}{ Rif } & \multicolumn{2}{|l|}{ Total } & 51 & $100 \%$ \\
\hline & \multicolumn{2}{|l|}{ PB4- } & 18 & $35.3 \%$ \\
\hline & & 11 & $21.6 \%$ \\
\hline & \multicolumn{2}{|l|}{ PB5- } & II & $21.6 \%$ \\
\hline & \multicolumn{2}{|l|}{ PB7- } & 6 & $11.8 \%$ \\
\hline & \multicolumn{2}{|c|}{ PB2-, PB5- } & 3 & $5.9 \%$ \\
\hline & \multicolumn{2}{|c|}{ PB6- } & 1 & $1.9 \%$ \\
\hline & \multicolumn{2}{|c|}{ Mutation not listed } & 1 & $1.9 \%$ \\
\hline \multirow[t]{7}{*}{$\mathrm{INH}$} & \multicolumn{2}{|l|}{ Total } & \multirow[t]{2}{*}{43} & \multirow[t]{2}{*}{$100 \%$} \\
\hline & katG & $\operatorname{inh} A$ & & \\
\hline & $315 \mathrm{TI}$ & & 33 & $76.7 \%$ \\
\hline & & $-15 T$ & 7 & $16.3 \%$ \\
\hline & \multirow{3}{*}{$\begin{array}{l}315 T I \\
\text { MUT }\end{array}$} & $-15 T$ & 1 & $2.3 \%$ \\
\hline & & & 1 & $2.3 \%$ \\
\hline & & MUT & I & $2.3 \%$ \\
\hline
\end{tabular}

\section{INH Genotyping}

The most common mutation on the LPA for INH resistance was the $\mathrm{S} 315 \mathrm{~T} 1$ mutation on the $k a t G$ gene which accounted for $44.7 \%(\mathrm{n}=21)$ of resistance (Table 2). Co-occurring mutations (S315T and either a T8A or C15T) accounted for a further $34 \%(n=16)$ of resistance. On the RT MTB RIF/ INH assay, the S315T mutation on the $k a t G$ gene was reported in $76.7 \%(\mathrm{n}=33)$ of isolates. The frequency of the inhA -15 mutation was $16.3 \%(\mathrm{n}=7)$. Co-occurring mutations (S315T and $-15 \mathrm{~T})$ accounted for a further $2.3 \%(\mathrm{n}=1)$ of resistance. Of the 75 isolates which demonstrated valid INH resistant results for both assays, $96.0 \%(\mathrm{n}=72)$ showed almost perfect agreement between the two assays (Kappa: 0.919).

\section{Discordant Genotype Results}

Targeted sequencing of the $r p o B, k a t G$ and $i n h A$ genes was performed on 10 isolates that reported discordant results between the LPA and RT MTB RIF/INH assays as listed in Table 4. The LPA incorrectly classified 6/10 isolates as Rif susceptible, among codon 511 and 533, while the RT MTB RIF/INH assay misclassified 2/10 isolates as Rif susceptible, among codon 526 and 531. The LPA missed a deletion in Codon 262 of the $k a t G$ gene in 2/10 isolates and incorrectly identified these two isolates as INH susceptible. In addition, 1/ 10 of isolates were incorrectly classified as INH resistant (demonstrated a dual S315T mutation in the $k a t G$ gene and a C15T mutation in the inhA gene). The RT MTB RIF/INH assay incorrectly classified $4 / 10$ isolates as INH susceptible. Deletions in Codon 262 were missed in three isolates as well 
Table 4 List of Discrepant Results and Validation with Sequencing

\begin{tabular}{|c|c|c|c|c|c|c|c|}
\hline \multirow[t]{2}{*}{ Obs } & \multirow{2}{*}{$\begin{array}{l}\text { Sequencing } \\
\text { rpoB }\end{array}$} & \multirow{2}{*}{$\begin{array}{l}\text { LPA } \\
\text { RIF }\end{array}$} & \multirow{2}{*}{$\begin{array}{l}\text { RT MTB } \\
\text { RIF/INH } \\
\text { RIF }\end{array}$} & \multicolumn{2}{|l|}{ Sequencing } & \multirow{2}{*}{$\begin{array}{l}\text { LPA } \\
\text { INH }\end{array}$} & \multirow{2}{*}{$\begin{array}{l}\text { RT MTB } \\
\text { RIF/INH } \\
\text { INH }\end{array}$} \\
\hline & & & & katG & $\operatorname{inh} A$ & & \\
\hline I & Codon 5II, Position 2: CTG-CCG & S & $R$ & Codon 315, Position 2: AGC-ACC & WT & $\mathrm{R}$ & $\mathrm{R}$ \\
\hline 2 & Codon 5II, Position 2: CTG-CCG & S & $\mathrm{R}$ & Deletion: Codon 262, Position I (A) & WT & S & $S$ \\
\hline 3 & Codon 5II, Position 2: CTG-CCG & S & $\mathrm{R}$ & Deletion: Codon 262, Position I (A) & WT & S & S \\
\hline 4 & Codon 5II, Position 2: CTG-CCG & S & $R$ & WT & WT & S & $S$ \\
\hline 5 & Codon 5II, Position 2: CTG-CCG & S & $R$ & WT & WT & S & S \\
\hline 6 & Codon 516, Position 2: GAC-GCC & $\mathrm{R}$ & $\mathrm{R}$ & Deletion: Codon 262, Position I (A) & WT & $\mathrm{R}$ & s \\
\hline 7 & Codon 526, Position 2: CAC-CGC & $\mathrm{R}$ & S & Codon 315, Position 2: AGC-ACC & WT & $\mathrm{R}$ & $\mathrm{R}$ \\
\hline 8 & Codon 526, Position 2: СAC-СТC & $\mathrm{R}$ & $\mathrm{R}$ & WT & WT & R & $\mathrm{s}$ \\
\hline 9 & Codon 53I, Position 2: TCG-TTG & $\mathrm{R}$ & s & WT & WT & $S$ & $\mathrm{~S}$ \\
\hline 10 & Codon 533, Position 2: CTG-CCG & S & $\mathrm{R}$ & $\begin{array}{l}\text { Deletion: Codon 262, Position I (A) } \\
\text { AND } \\
\text { Codon 3I5, Position 2: AGC-ACC }\end{array}$ & WT & $\mathrm{R}$ & S \\
\hline
\end{tabular}

Notes: $\mathrm{S}$ denotes susceptible, $\mathrm{R}$ denotes resistant, LPA denotes line probe assay, INH denotes isoniazid, RIF denotes rifampicin, WT denotes wild-type pattern, RT-MTB refers to the Abbott RealTime MTB assay. Results highlighted in green demonstrate the correct result (as determined by sequencing) while results highlighted in red demonstrate the incorrect result. rpoB, inhA and katG refer to genes in the Mycobacterium tuberculosis genome and are therefore italicized.

as in an isolate where the deletion co-occurred with an S315T1 mutation.

These results demonstrate that with the SOC LPA testing, six isolates were incorrectly identified as drug susceptible (Rif resistance was confirmed both by the RT MTB $\mathrm{RIF} / \mathrm{INH}$ assay and sequencing) and another isolate was incorrectly identified resistant to INH (susceptibility to INH was confirmed both by the RT MTB RIF/INH assay and sequencing). If the RT MTB RIF/INH results have been used in the diagnostic algorithm, six isolates would have been incorrectly identified as fully susceptible (Rif resistance was confirmed in two isolates and INH resistance in the other four isolates by sequencing).

\section{Discussion}

For Rif, the S531L mutation is the most common mutation in the $r p o B$ gene accounting for $29 \%-80 \%$ of global resistance $^{19-21}$ and is considered a high-confidence mutation. $^{22}$ The isolates selected for this study were a combination of those containing this $\mathrm{S} 531 \mathrm{~L}$ and $k a t G$ (S315T) mutations in addition to some with less frequent rpoB D516V and H526Y mutations. These mutations appear to vary widely across geographical areas as demonstrated by Van Deun A et $\mathrm{al}^{23}$ who reported D516V mutation frequencies of $3.4 \%$ and $7.1 \%$; and $\mathrm{H} 526 \mathrm{Y}$ mutation frequencies of 9.7\% and 2.4\% from Bangladesh and Kinshasa, respectively. Although both assays produced the same number of indeterminate results $(\mathrm{n}=10)$, the RT MTB RIF/INH was able to correctly detect Rif and/or INH susceptibility in one more isolate than the LPA, thereby providing more accurate genotyping result reporting based on reference sequencing outputs. For the Rif only and INH only resistant isolates, the RT MTB RIF/INH assay demonstrated better performance on Rif resistance detection than the LPA (21 vs 19), while both assays demonstrated similar performance for INH resistance detection. Although both assays demonstrated good agreement for Rif resistance detection among the more frequently occurring mutations, the RT MTB RIF/INH assay was able to provide additional information on the rare mutations in codon 511 on 5 more isolates than the LPA assay. Deficiencies of the RT MTB RIF/INH assay include missed mutations in codons 526 (global frequency of $0.2 \%-1 \%)^{20,21}$ and S531L (this mutation was detected in 11/12 [92\%] isolates). A misdiagnosis for Rif on the RT MTB RIF/INH assay has also been demonstrated previously on H526D, H526R and L533P mutations. ${ }^{24,25}$ For the 10 discordant isolates, and using sequencing as the reference, the LPA misclassified five isolates for Rif resistance profiling versus 2 on the RT MTB RIF/INH assay. The LPA, therefore, missed three additional Rif resistant isolates as compared to the RT MTB RIF/INH assay. This is in line with a previous study that demonstrated the LPA misses some mutations (del 517, D516Y, S522P, L530L, S531L and L553P) in the $r p o B$ gene. ${ }^{26}$ Of the five isolates, the missed mutation is the minimal-confidence L511P mutation (demonstrated to occur at a frequency of $3 \%)^{20}$ in $45.5 \%$ of isolates. The banding patterns on the LPA for these five isolates did, however, display weaker WT2 band staining than the other WT bands on the strips, which 
Table 5 Summary of High-Throughput Rif and INH Genotyping Technologies

\begin{tabular}{|c|c|c|c|c|c|}
\hline Company & Platform & $\begin{array}{l}\text { Assay } \\
\text { (Throughput) }\end{array}$ & LOD** & Target & Multipurpose Capability \\
\hline \multirow[t]{2}{*}{ Abbott } & \multirow[t]{2}{*}{$\begin{array}{l}\text { m2000 system } \\
(\mathrm{sp} / \mathrm{rt})\end{array}$} & $\begin{array}{l}\text { RT-MTB ( } 94 \text { specimen/ } \\
\text { run)*28-30 }\end{array}$ & $2.5-35 \mathrm{cfu} / \mathrm{mL}$ & $\begin{array}{l}\text { MTBC: IS6IIO and } \\
\text { pab gene }\end{array}$ & \multirow{2}{*}{$\begin{array}{l}\text { HIV-I, HBV, HCV, CMV, EBV } \\
\text { HIV-I Qualitative, High Risk } \\
\text { HPV, CT/NG, and CT }\end{array}$} \\
\hline & & $\begin{array}{l}\text { RT- Rif/INH }(22 \\
\text { specimens/run })^{* 25,31}\end{array}$ & $60 \mathrm{cfu} / \mathrm{mL}$ & $\begin{array}{l}\text { RIF-INH: rpoB, katG } \\
\text { and inhA }\end{array}$ & \\
\hline \multirow[t]{3}{*}{ Roche } & \multirow[t]{3}{*}{ Cobas $68 / 8800$} & cobas MTB* & $7.6-8.8 \mathrm{cfu} / \mathrm{mL}$ & $\begin{array}{l}\text { MTBC: } 16 \mathrm{~S} \text { rRNA and } \\
5 \text { esx }\end{array}$ & \multirow{3}{*}{$\begin{array}{l}\text { HIV-I/2, HCV, HBV, CMV, MPX, } \\
\text { WNV, Zika, DPX, CT-NG/HIV-I, } \\
\text { HCV, HBV, CMV, CT-NG, HPV, } \\
\text { HIV-I/2 qual., MPX, WNV, TVI } \\
\text { MG }\end{array}$} \\
\hline & & cobas Rif//NH* & & $\begin{array}{l}\text { RIF-INH: rpoB, katG } \\
\text { and inhA }\end{array}$ & \\
\hline & & cobas MAI* & & & \\
\hline \multirow[t]{2}{*}{ Cepheid } & \multirow[b]{2}{*}{$\begin{array}{l}\text { GeneXpert: } \\
\text { Gx I (I } \\
\text { specimen/2hrs) } \\
\text { Gx4 } \\
\text { Gx16 } \\
\text { Gx48 } \\
\text { Gx80 }\end{array}$} & Xpert MTB/RIF ${ }^{32,33}$ & $50-165 \mathrm{cfu} / \mathrm{mL}$ & rpoB with 5 probes & \multirow{2}{*}{$\begin{array}{l}24 \text { assays in separate cartridge } \\
\text { format }\end{array}$} \\
\hline & & $\begin{array}{l}\text { Xpert MTB/RIF } \\
\text { Ultra }^{34}\end{array}$ & $5-25 \mathrm{cfu} / \mathrm{mL}$ & $\begin{array}{l}\text { IS6III, ISI08I and } \\
\text { rpoB with } 4 \text { probes }\end{array}$ & \\
\hline $\mathrm{BD}$ & BD MAX & MDR-TB ${ }^{35}$ & $\begin{array}{l}\text { MTBC: } 0.5 \mathrm{cfu} / \mathrm{mL} \\
\text { RIF-INH: } 6 \mathrm{cfu} / \mathrm{mL}\end{array}$ & $\begin{array}{l}\text { MTBC: IS6II0, } \\
\text { ISI08I and deVR } \\
\text { RIF-INH: rpoB, katG } \\
\text { and inhA }\end{array}$ & $\begin{array}{l}\text { MRSA, Cdiff, Staph SR, Enteric } \\
\text { bacterial, Enteric Viral }\end{array}$ \\
\hline $\begin{array}{l}\text { Bruker } \\
\text { (HainLifeSciences) }\end{array}$ & Fluorocycler & $\mathrm{MTBDR}^{36-38}$ & $22 \mathrm{cfu} / \mathrm{mL}$ & rpoB, katG and inhA & $\begin{array}{l}\text { HSV, Fungiplex (Universal, } \\
\text { Aspergillus, Candida), Carbaplex }\end{array}$ \\
\hline
\end{tabular}

Notes: *performed as independent assays. **under WHO review.

usually occurs in the case of an L511P or L533P mutation (personal communication with HAIN Lifesciences). In addition, a similar feint WT8 band was displayed for the isolate which contained the L533P mutation. These strips highlight the requirement for experienced laboratory personnel for the interpretation of banding patterns.

For INH, both assays demonstrated almost perfect agreement but the LPA was able to provide one additional INH resistance profile compared to the RT MTB RIF/INH assay. The most common mutation detected by both assays is the $\mathrm{S} 315 \mathrm{~T}$ mutation which occurs at a frequency of $64 \%{ }^{27}$ The RT MTB RIF/INH assay misclassified four isolates (compared to sequencing for INH) compared to three on the LPA. On the LPA, for the culture isolate, which demonstrated resistance in the katG region, the intensity of the MUT1 band indicates that a mixed infection may be present. On the RT MTB RIF/INH assay, the deletion that was missed (Codon 262, Position 1 (A)) in the $k a t G$ gene is a deletion that was also missed by the LPA in $2 / 4(50 \%)$ of isolates displaying this mutation in this study. The RT MTB RIF/INH assay also missed an S315T mutation in the kat $G$ gene in one isolate but this mutation was correctly detected in the other 19 (95\%) isolates.

Alternative molecular technologies other than the LPA are becoming available (WHO interim report) and provide resistance profiles for Rif and INH, which are automated with high-throughput capability as outlined in Table 5 . These technologies include the cobas MTB and MTB RIF/INH assays, FluoroType MDRTB, BD MAX MTBDR and Abbott RT MTB and MTB RIF/INH assays'. All these assays are based on real-time PCR. The cobas ${ }^{\circledR}$ MTB assay (Roche Molecular Diagnostics, Pleasanton, CA, USA) detects MTBC by targeting the 16S rRNA and 5 esx genes and can generate results for 94 tests in 3.5 hours. Testing on the cobas MTB RIF/INH assay can be performed in an additional 3.5 hours. ${ }^{18}$ The MAX MDR-TB is performed on the BD MAX System to detect MTBC through targeting IS6110, IS1081 and devR ${ }^{19}$ with 24 specimens tested per batch and results reported within 4 
hours. The FluoroType ${ }^{\circledR}$ MTBDR assay (Hain Lifescience, Nehren, Germany) uses LATE-PCR amplification and lights-on/lights-off chemistry to detect MTBC by targeting the $r p o B$ gene. ${ }^{19}$ Results are generated within 4 hours and 94 specimens tested in a batch. Rif and INH resistance profiling for all three assays (cobas ${ }^{\circledR}$ MTB RIF/INH, FluoroType $^{\circledR}$ MTBDR and BD MDR-TB) is performed through the detection of mutations in the $r p o B$ gene, $k a t G$ gene and inhA promoter region. Both the BD MDRTB and the FluoroType MTBDR offer the advantage of differentiating between high- and low-level INH resistance but only the FluoroType MTBDR results include specific mutations identified for the three gene targets. The Xpert and BD tests are "closed" cartridge and cassette-based assays, whereas the RT MTB assay, RT MTB RIF/INH and cobas ${ }^{\circledR}$ MTB and MTB-RIF/INH are assays that may be performed independently. The Abbott, Roche and Cepheid platforms also address system efficiencies through multidisease testing available on a single platform to potentially simplify workflow, increase access and improve disease management. ${ }^{13}$ The Fluorocycler as with the current Xpert and Ultra assays isolate whole MTBC from inactivated specimens prior to DNA extraction.

\section{Conclusions}

Overall, the RT MTB RIF/INH demonstrated good agreement with the LPA and compared better with sequencing on discordant isolates than the LPA. RT MTB RIF/INH, therefore, shows good potential to be used in current testing algorithms for the determination of Rif and INH clinically relevant mutations.

\section{Acknowledgments}

The authors would like to thank Kate Shearer (Department of Molecular Medicine and Haematology, University of the Witwatersrand, Johannesburg, SA) and Gabriel Eisenberg (Department of Molecular Medicine and Haematology, University of the Witwatersrand, Johannesburg, SA) for statistical analysis input, Robert Coombs (University of Washington, Seattle and the AIDS clinical Trial Group) for input into the internal LPA strip-reading experiment, HAIN Lifesciences for providing the MTBDRplus kit (free of charge), Abbott Molecular for providing the MTB Real Time RIF/INH kits (free of charge).

\section{Disclosure}

Lesley Scott reports Abbott Molecular and Hain LifeSciences provided kits for assay evaluation and funding for laboratory support to retrieve bio-bank specimens. In addition, Professor Lesley Scott has a patent USP 8709712 (related to standardised material for molecular TB tests) with royalties paid to University of the Witwatersrand, Johannesburg, South Africa.

Wendy Stevens, Lesley Scott and Anura David received funding support from the South African Medical Research Council with funds received from the South African National Department of Health, and the UK Medical Research Council, with funds received from the UK Government's Newton Fund under the UK/South Africa Newton Fund (no. 015NEWTON TB). The authors report no other potential conflicts of interest for this work.

\section{References}

1. Tanna GLD, Khaki AR, Theron G, et al. Effect of Xpert MTB/RIF on clinical outcomes in routine care settings: individual patient data meta-analysis. Lancet Glob Health. 2019;7(2):91-99. doi:10.1016/ S2214-109X(18)30458-3

2. Berhanu RH, David A, da Silva P, et al. Performance of Xpert MTB/ RIF, Xpert Ultra, and Abbott Real Time MTB for the diagnosis of pulmonary tuberculosis in a high HIV burden setting. $J$ Clin Microbiol. 2018;56(12):e00560-e00518. doi:10.1128/JCM.00560-18

3. Bai Y, Wang Y, Shao C, Hao Y, Jin Y. GenoType MTBDRplus Assay for Rapid Detection of Multidrug Resistance in Mycobacterium tuberculosis: A Meta-Analysis. PLoS One. 2016;11:3.

4. Meaza A, Kebede A, Yaregal Z, et al. Evaluation of genotype MTBDRplus VER 2.0 line probe assay for the detection of MDR-TB in smear positive and negative sputum samples. $B M C$ Infect Dis. 2017;17(1):280. doi:10.1186/s12879-017-2389-6

5. Seifert M, Ajbani K, Georghiou SB, et al. A Performance Evaluation of MTBDRplus (version 2) for the Diagnosis of Multidrug-resistant Tuberculosis. Int $J$ Tuberc Lung Dis. 2016;20(5):631-637. doi:10.5588/ijtld.15.0788

6. Barnard M, Gey van Pittius NC, van Helden PD, Bosman M, Coetzee G, Warren RM. The Diagnostic Performance of the GenoType MTBDRplus Version 2 Line Probe Assay Is Equivalent to That of the Xpert MTB/RIF Assay. Journal Clin Microbiol. 2012;50(11):3712-3716. doi:10.1128/JCM.01958-12

7. WHO. Molecular Line Probe Assays for Rapid Screening of Patients at Risk of Multi-Drug Resistant Tuberculosis (MDR-TB). Geneva, Switzerland: World Health Organization; 2008.

8. Madhuri K, Deshpande S, Dharmashale S, Bharadwaj R. Utility of Line Probe Assay for the Early Detection of Multidrug-Resistant Pulmonary Tuberculosis. J Glob Infect Dis. 2015;7(2):60-65. doi:10.4103/0974-777X.157237

9. Ahmed S, Shukla I, Fatima N, Varshney SK, Shameem M. Evaluation of genotype MTBDRplus line probe assay in detection of rifampicin and isoniazid resistance in comparison to solid culture drug susceptibility testing in a tertiary care centre of western Uttar Pradesh. Indian J Med Microbiol. 2017;35:568-574.

10. Crudu V, Stratan E, Romancenco E, Allerheiligen V, Hillemann A, Moraru N. First evaluation of an improved assay for molecular genetic detection of tuberculosis as well as rifampin and isoniazid resistances. J Clin Microbiol. 2012;50(4):1264-1269. doi:10.1128/ JCM.05903-11

11. Maningi NE, Malinga LA, Antiabong JF. Comparison of line probe assay to BACTEC MGIT 960 system for susceptibility testing of first and second-line anti-tuberculosis drugs in a referral laboratory in South Africa. BMC Infect Dis. 2017;17:795. 
12. Scott LE, Carmona S, Gous N, Horsfield P, MacKay M, Stevens W. Use of a Prequalification Panel for Rapid Scale-Up of High-Throughput HIV Viral Load Testing. J Clin Microbiol. 2012;50(12):4083-4086. doi:10.1128/JCM.01355-12

13. Wang MG, Xue M, Wu SQ, et al. Abbott RealTime MTB and MTB RIF/INH assays for the diagnosis of tuberculosis and rifampicin/ isoniazid resistance. Infect Genet Evol. 2019;71:54-59. doi:10.1016/ j.meegid.2019.03.012

14. Scott LE, David A, Noble L, et al. Performance of the Abbott RealTime MTB and MTB RIF/INH Assays in a Setting of High Tuberculosis and HIV Coinfection in South Africa. $J$ Clin Microbiol. 2017;55(8):2491-2501. doi:10.1128/JCM.00289-17

15. Tam KK, Leung K, To SW, et al. Direct detection of Mycobacterium tuberculosis and drug resistance in respiratory specimen using Abbott RealTime MTB detection and RIF/INH resistance assay. Diagn Microbiol Infect Dis. 2017;89(2):118-124. doi:10.1016/j.diagmicrobio.2017.06.018

16. Kostera J, Leckie G, Abravaya K, Wang H. Performance of the Abbott RealTime MTB RIF/INH resistance assay when used to test Mycobacterium tuberculosis specimens from Bangladesh. Infect Drug Resist. 2018;11(11):695-699. doi:10.2147/IDR.S158953

17. GenoType MTBDRplus Instructions for Use. Hain Lifesciences; 2018.

18. GmbH HL GenoType MTBDR Plus, VER 2.0, Instructions for Use, IFU-304A-09 Germany2019. Available from: https://www.hainlifescience.de/en/instructions-for-use.html. Accessed September 4, 2020.

19. Zaw MT, Emran NA, Lin Z. Mutations inside rifampicin-resistance determining region of $\mathrm{rpoB}$ gene associated with rifampicin-resistance in Mycobacterium tuberculosis. J Infect Public Health. 2018;11 (5):605-610. doi:10.1016/j.jiph.2018.04.005

20. Kapur V, Li L, Lordanescu S, et al. Characterization by Automated DNA Sequencing of Mutations in the Gene (rpoB) Encoding the RNA Polymerase 3 Subunit in Rifampin-Resistant Mycobacterium tuberculosis Strains from New York City and Texas. J Clin Microbiol. 1994;32 (4):1095-1098. doi:10.1128/JCM.32.4.1095-1098.1994

21. Georghiou SB, Seifert M, Catanzaro D, et al. Frequency and Distribution of Tuberculosis Resistance-Associated Mutations between Mumbai, Moldova, and Eastern Cape. Antimicro Agents Chemother. 2016;60:3994-4004.

22. Miotto P, Tessema B, Tagliani E, et al. A standardised method for interpreting the association between mutations and phenotypic drug resistance in Mycobacterium tuberculosis. Eur Respir J. 2017;50 (6):1701354. doi:10.1183/13993003.01354-2017

23. Van Deun A, Aung KJ, Bola V, et al. Rifampin drug resistance tests for tuberculosis: challenging the gold standard. J Clin Microbiol. 2013;51(8):2633-2640. doi:10.1128/JCM.00553-13

24. Ruiz P, Causse M, Vaquero M, Guitierrez JB, Casal M. Evaluation of a new automated Abbott RealTime MTB RIF/INH assay for qualitative detection of rifampicin/isoniazid resistance in pulmonary and extra-pulmonary clinical samples of Mycobacterium tuberculosis. Infect Drug Resist. 2017;10:463-467. doi:10.2147/IDR.S147272

25. Hoffmann-Thiel S, Molodtsov N, Duffner C, et al. Capacity of Abbott RealTime MTB RIF/INH to detect rifampicin- and isoniazid-resistant tuberculosis. Int $J$ Tuberc Lung Dis. 2019;23 (4):458-464. doi:10.5588/ijtld.18.0615

Infection and Drug Resistance

\section{Publish your work in this journal}

Infection and Drug Resistance is an international, peer-reviewed openaccess journal that focuses on the optimal treatment of infection (bacterial, fungal and viral) and the development and institution of preventive strategies to minimize the development and spread of resistance. The journal is specifically concerned with the epidemiology of
26. Rahman A, Sahrin M, Afrin S, et al. Comparison of Xpert MTB/RIF Assay and GenoType MTBDRplus DNA Probes for Detection of Mutations Associated with Rifampicin Resistance in Mycobacterium tuberculosis. PLoS One. 2016;11(4):4. doi:10.1371/journal.pone.0152694

27. Seifert M, Catanzaro D, Catanzaro A, Rodwell TC. Genetic Mutations Associated with Isoniazid Resistance in Mycobacterium tuberculosis: A Systematic Review. PLoS One. 2015;10(3):e0119628. doi:10.1371/journal.pone.0119628

28. Vinuesa V, Navarro D, Poujois S, Zaragoza S, Borras R. Performance characteristics of the new Abbott Real Time MTB assay for detection of Mycobacterium tuberculosis complex in respiratory specimens. Diagn Microbiol Infect Dis. 2016;84(3):212-214. doi:10.1016/j. diagmicrobio.2015.11.001

29. Tang N, Frank A, Pahalawatta V, et al. Analytical and clinical performance of Abbott RealTime MTB, an assay for detection of Mycobacterium tuberculosis in pulmonary specimens. Tuberculosis. 2015;95(5):613-619. doi:10.1016/j.tube.2015.05.010

30. Chen JH, She KK, Kwong TC, et al. Performance of the new automated Abbott RealTime MTB assay for rapid detection of Mycobacterium tuberculosis complex in respiratory specimens. Eur J Clin Microbiol Infect Dis. 2015;34(9):1827-1832. doi:10.1007/ s10096-015-2419-5

31. Kostera J, Leckie G, Tang N, et al. Analytical and clinical performance characteristics of the Abbott RealTime MTB RIF/INH Resistance, an assay for the detection of rifampicin and isoniazid resistant Mycobacterium tuberculosis in pulmonary specimens. Tuberculosis. 2016;101:137-143. doi:10.1016/j.tube.2016.09.006

32. Helb D, Jones M, Story E, et al. Rapid Detection of Mycobacterium tuberculosis and Rifampin Resistance by Use of On-Demand, Near-Patient Technology. J Clin Microbiol. 2010;48(1):229-237. doi:10.1128/JCM.01463-09

33. Blakemore R, Story E, Helb D, et al. Evaluation of the analytical performance of the Xpert MTB/RIF assay. J Clin Microbiol. 2010;48 (7):2495-2501. doi:10.1128/JCM.00128-10

34. Chakravorty S, Simmons AM, Rowneki M, et al. The New Xpert MTB/RIF Ultra: improving Detection of Mycobacterium tuberculosis and Resistance to Rifampin in an Assay Suitable for Point-of-Care Testing. mBio. 2017;8(4):e00812. doi:10.1128/mBio.00812-17

35. Murray P, Cooper C, Maus C. Comparative Performance of BD MAX MDR-TB and Cepheid Xpert MTB/RIF Assays. J Clin Microbiol. 2019;57(9):e00779. doi:10.1128/JCM.00779-19

36. de Vos M, Derendinge RB, Dolby T, et al. Diagnostic accuracy and utility of FluoroType MTBDR, a new molecular assay for multidrug-resistant tuberculosis. J Clin Microbiol. 2018;56(9). doi:10.1128/JCM.00531-18

37. Hillemann D, Haasis C, Andres S, Behn T, Kranzer K. Validation of the FluoroType MTBDR Assay for Detection of Rifampin and Isoniazid Resistance in Mycobacterium tuberculosis Complex Isolates. $J$ Clin Microbiol. 2018;56(6):e00072. doi:10.1128/JCM.00072-18

38. Obasanya J, Lawson L, Edwards T, et al. FluoroType MTB system for the detection of pulmonary tuberculosis. ERJ Open Res. 2017;3:2.

\section{Dovepress}

antibiotic resistance and the mechanisms of resistance development and diffusion in both hospitals and the community. The manuscript management system is completely online and includes a very quick and fair peerreview system, which is all easy to use. Visit http://www.dovepress.com/ testimonials.php to read real quotes from published authors. 